\title{
Research on Characteristics and Heating Modes of Heat Pump System Yang DU ${ }^{1, a}$, Shan $\mathrm{TU}^{1, \mathrm{~b}}$, Hongjuan WANG ${ }^{1, c}$ \\ ${ }^{1}$ School of Energy and Power Engineering , Xi'an Jiaotong University, Xi'an, 710049, China \\ aemail: dy19901027@stu.xjtu.edu.cn, bemail: tushan@mail.xjtu.edu.cn, cemail: wanghongjuan@stu.xjtu.edu.cn
}

\section{Keywords: Absorption Heat Pump; Thermal Efficiency; Heating Modes}

\begin{abstract}
Heat pump can recycle waste heat and improve waste heat utilization rate of thermal power plant. In the design of heat pump, different heating schemes should be selected to match different demands of heating users. In this paper, based on actual heat supply network of a northern city and the thermodynamic system diagram of a 330 MW unit, the change of internal characteristics of the heat pump was analyzed with the variation of supply and return water temperature of the heat supply network. Studies show that the best supply and return water temperature are respectively $45^{\circ} \mathrm{C}$ and $80^{\circ} \mathrm{C}$. On this basis, the optimal working way was found. For different heat users, reasonable heating scheme should be chosen to maximize the benefits and realize win-win situation of heat and electricity.
\end{abstract}

\section{Introduction}

Heat pump technology can recycle waste heat from industry, daily life and power plant to improve waste heat utilization rate[1][2]. The heat pump prototype used for heating was first put forward by L.Kelvin in 1852[3]. For power industry, actual thermal efficiency of large-scale thermal power plant in our country is $40 \%$, namely about $60 \%$ of the heat is taken away by the condenser cooling water and discharged to the environment[4]. Power plant cooling water temperature is $20 \sim 50^{\circ} \mathrm{C}$, it belongs to low grade energy and contains a lot of energy. The first kind of absorption heat pump is very suitable for thermal power plant which has both a large number of low temperature waste heat and high temperature heat source. Because the heat pump driven by high temperature thermal energy can recycle low temperature waste heat and then improve it to medium temperature. In this way, the utilization rate of heat energy will be improved. According to the working medium, heat pump units can be divided into lithium bromide absorption and ammonia absorption, which can be chosen according to the specific application requirement[5]. Steam source of thermal power plant is sufficient, and the lithium bromide absorption heat pump unit has better energy saving effect. Depending on the position of heat pump unit in heat supply network, the heating mode of heat pump can be divided into distributed and centralized. The combination of centralized heat pump and heat exchanger heating way was adopted, namely part of the heat supply steam extraction drives the heat pump to recycle the waste heat carried by cooling water and preliminarily preheat network backwater, and the other part goes into the heat exchanger of traditional heat supply network to further heat the backwater until it meets the demand of supply water temperature. The principle of cascade heating way supports the basis of absorption heat pump, so the supply and return water temperatures of the heat supply network decide the efficiency of heat pump [6].

In this paper, the effects of different supply and return water temperatures on thermal economy of heat pump were analyzed, and the optimal way of working was found. When heat pump and heat exchanger meet the different demands of heating, reasonable heating scheme is selected.

\section{The model of heat pump system}

Research of this paper is based on the actual heat supply network of a northern city in China and the model CZK330/261-16.7/0.5/537/537 of the $330 \mathrm{MW}$ coal-fired unit. Parameters were selected 
according to the network run log, the supply and return water temperatures are $102^{\circ} \mathrm{C}$ and $65^{\circ} \mathrm{C}$ respectively, circulating water quantity is $4528.7 t \cdot h^{-1}$, and heating capacity is $702 G J \cdot h^{-1}$. According to thermal physical data of lithium bromide aqueous, the outlet water temperature of lithium bromide absorption heat pump is generally less than $80^{\circ} \mathrm{C}$, so the temperature of network is promoted from $65^{\circ} \mathrm{C}$ to $80^{\circ} \mathrm{C}$ by heat pump, and the higher temperature is decided by heat-supply water heater. The parameters determine the characteristics of heat pump and heat exchanger, thus determine the overall features of the set. We assume that heating load is constant and the extraction location is the No. 4 extraction whose steam pressure is $0.976 \mathrm{MPa}$, the influences of different supply and return water temperatures of heat supply network on thermal efficiency were discussed. Equidistant nodes within the range of supply and return water temperature were taken, then the total amount of driving steam, the steam consumption of network heater, the COP of heat pump system on each node were got.

The specific calculation steps of internal parameters in heat pump system are as below. Figure 1 is the working process of single-effect lithium bromide absorption heat pump.

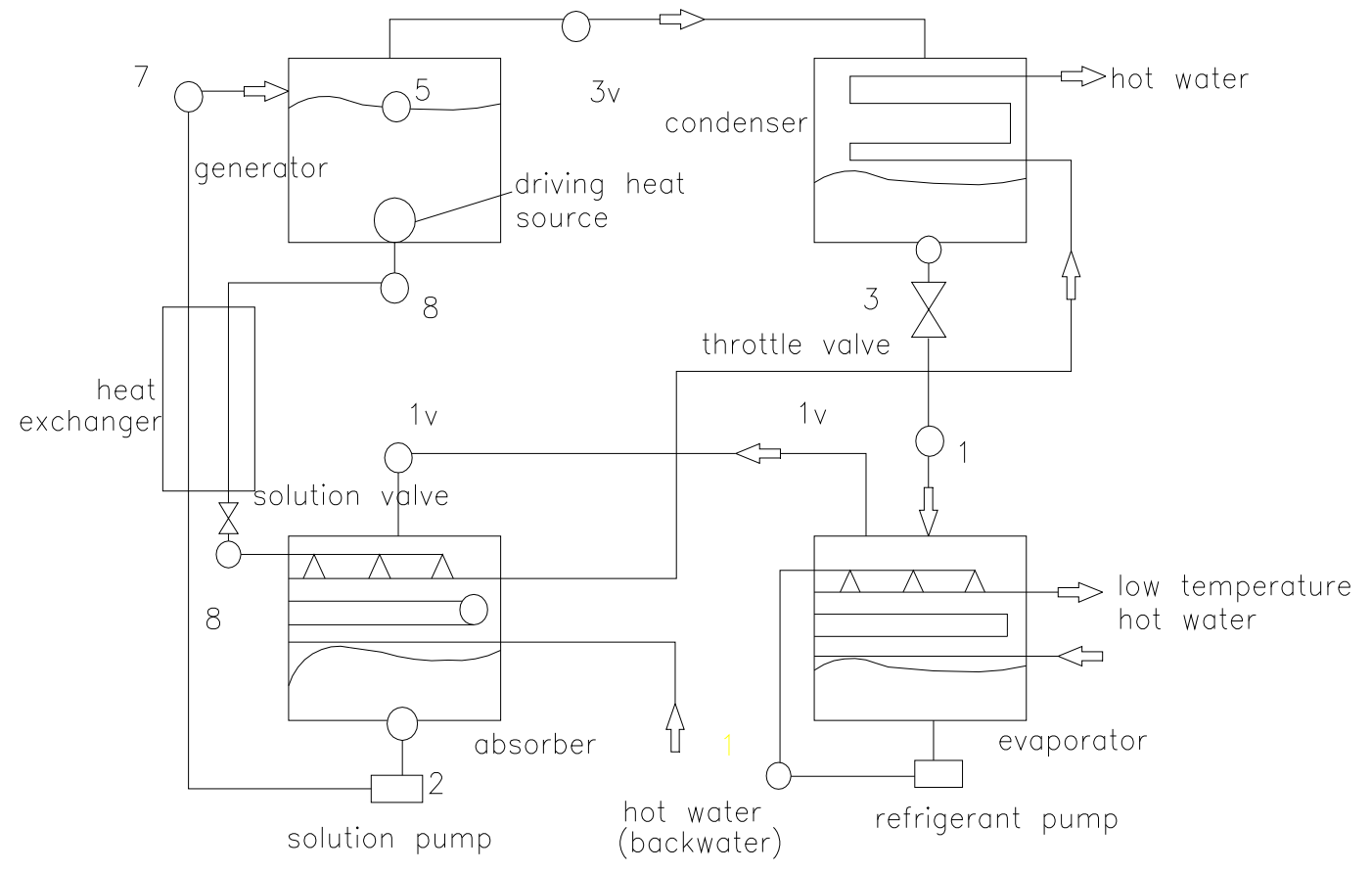

Fig.1. Working process of single-effect lithium bromide absorption heat pump

When the 330 MW coal-fired unit is under rated condition, the circulating cooling water temperature in the condenser outlet or the evaporator inlet of the heat pump system is $44{ }^{\circ} \mathrm{C}$. The return water temperature is $65^{\circ} \mathrm{C}$, and the No. 4 steam extraction whose pressure is $0.976 \mathrm{MPa}$ is the driving heat source of heat pump. According to the terminal difference of heat exchanger, the circulating cooling water temperature in the evaporator outlet is $30^{\circ} \mathrm{C}$, and the heat-supply water temperature in the heat pump outlet is $80^{\circ} \mathrm{C}$.On this basis, the evaporation temperature and condensation temperature are $28{ }^{\circ} \mathrm{C}$ and $83^{\circ} \mathrm{C}$ respectively. The condensation temperature of the $0.976 \mathrm{MPa}$ steam is $179^{\circ} \mathrm{C}$.If the temperature difference between motive steam and concentrated solution in the generator outlet is $26.3^{\circ} \mathrm{C}$, then the temperature of the concentrated solution in the generator outlet is $T_{4}=152.7^{\circ} \mathrm{C}$. The backwater is first heated by the absorber and then heated by the condenser. And the hot water temperature in the absorber outlet is about the average temperature of supply water and return water, which is $72.5^{\circ} \mathrm{C}$.If the temperature difference between the dilute solution and hot water in the absorber outlet is $3.5^{\circ} \mathrm{C}$, the dilute solution temperature in the absorber outlet is $T_{2}=76^{\circ} \mathrm{C}$. Due to some factors such as crystallization risk, the rich solution temperature in the heat exchanger outlet is higher than dilute solution temperature in the heat exchanger inlet. According to the temperature and pressure values of each point, the water or lithium bromide aqueous solution tables containing thermal and physical properties were checked. And then the 
enthalpy value at every point was obtained.

\section{Influence of supply water temperature change of heat-supply network on unit thermal efficiency}

When the amount of heat supply is constant, the variation of heat-supply network supply water temperature influences the heat supply temperature difference and thus changes the mass flow rate of heat supply network circulating water. It is assumed that return water temperature of heat supply network and the water temperature in heat pump outlet are constantly $65^{\circ} \mathrm{C}$ and $80^{\circ} \mathrm{C}$. When the supply water temperature changes from $80^{\circ} \mathrm{C}$ to $116^{\circ} \mathrm{C}$, the influence of supply water temperature of heat supply network on unit thermal efficiency was analyzed. Specially, the sum of the required mass flow rate of heat pump motive steam and the mass flow rate of steam consumption in heat supply network heat exchanger was calculated. Figure 2 was gotten according to the calculation results of the total steam consumption amount on each node.

From the Figure 2, when the amount of heat supply and return water temperature of heat supply network is constant, higher supply water temperature of heat supply network leads to more heat supply steam extraction and variable working condition of the unit. The equivalent enthalpy drop method shows that more steam extraction results in less actual work of steam unit and less electricity. So when supply water temperature of heat supply network is $80^{\circ} \mathrm{C}$, the heat pump supplies all heating load and steam extraction mass flow rate is least, and then the thermal efficiency of unit is highest.

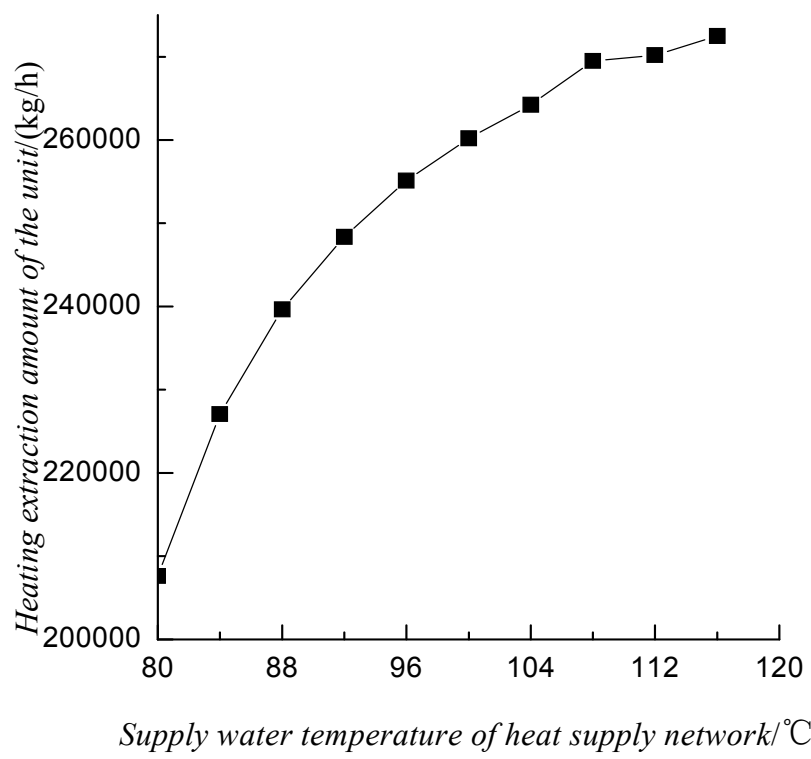

Fig.2. Relationship between supply water temperature of heat supply network and the heating steam extraction amount of the unit

\section{Influence of return water temperature change of heat-supply network on unit thermal efficiency}

When the amount of heat supply is constant, the variation of return water temperature similarly changes heating temperature difference and thus changes the mass flow rate of heat supply network circulating water. However, the change of backwater temperature has its particularity, which is different from the change of supply water temperature. It changes respective heating load share of heat pump and peak heater. The change of temperature difference directly changes the hot water temperature in absorber outlet of the heat pump, and then changes parameters at various points inside the heat pump and the COP. Assuming that the supply water temperature and the water temperature in the heat pump outlet are constantly $102^{\circ} \mathrm{C}$ and $80^{\circ} \mathrm{C}$. The lowest return water 
temperature is equal to the low temperature heat source temperature of heat pump, which is $45^{\circ} \mathrm{C}$. A node is selected at every $5^{\circ} \mathrm{C}$ when return water temperature changes from $45^{\circ} \mathrm{C}$ to $65^{\circ} \mathrm{C}$. Internal parameters of heat pump were calculated at each node. Then heat pump COP of each node was gotten to study the influence of return water temperature change on the thermal efficiency.

The calculation results of the heating steam extraction amount of the unit and the influence of the return water temperature change on heat pump COP are shown in Figure 3.According to Figure 3 , we can see that when the supply water temperature and heating amount is constant, heat pump COP reduces and heat supply steam extraction amount increases with the increase of backwater temperature. The reduction of heat pump COP will reduce its work ability. With the increase of heating steam extraction amount, the thermal efficiency of the unit will reduce. So only considering the perspective of economy, higher heat pump COP and less heat supply steam extraction amount results in better economy. Namely the optimal heat-supply backwater temperature is $45^{\circ} \mathrm{C}$.

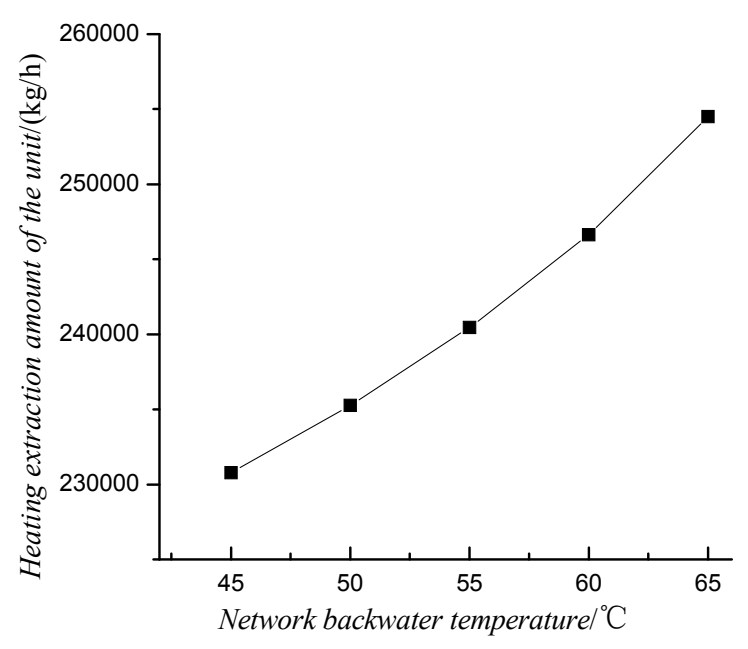

(a) Heat supply steam extraction amount

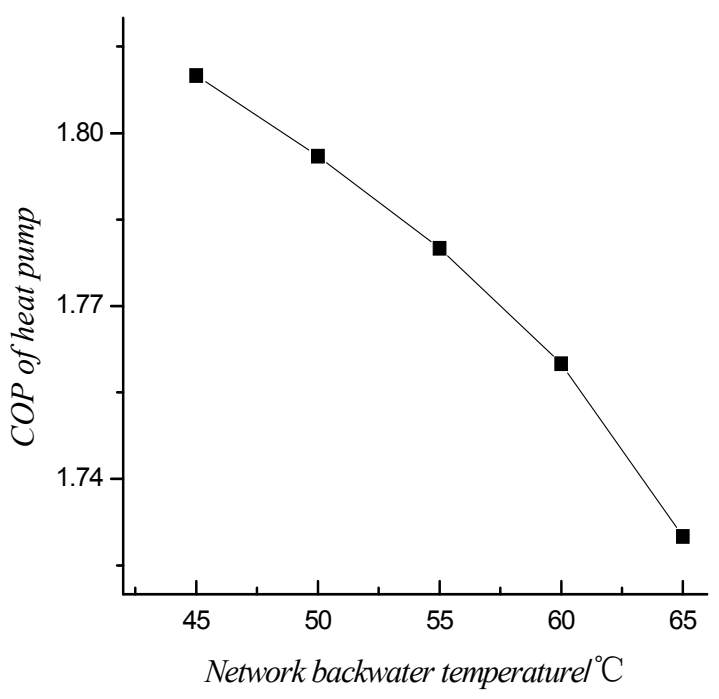

(b) COP of heat pump

Fig.3. Effect of heat-supply network backwater temperature on heat supply steam extraction amount and COP of heat pump

\section{Heating scheme and corresponding user type under different heating requirements}

Calculation results in part 2 singly consider economy of heat-supply network. But for the heat 
scheme corresponding to the ideal optimal thermal efficiency of heating, its heating parameters may not satisfy the requirements of heat users. On the basis that the heating load of the original heat-supply network is constant, we consider heat supply requirements of heat users and then change the return water temperature. The following three different heating schemes are designed.

Scheme a meets the demand of heat-supply load. For this scheme heat supply temperature and return water temperature are not taken into consideration. And then optimal value according to calculated curve is taken to enhance the thermal efficiency. It means that the supply and return water temperature are $80{ }^{\circ} \mathrm{C}$ and $45{ }^{\circ} \mathrm{C}$. Heat pump COP is 1.81 in this condition. Because of the lower backwater temperature needs improvement of heat transfer technology in heat-supply network side, this scheme is suitable for heat user who has lower heating temperature requirement, short heating distance, and strong heating temperature control ability.

Scheme $b$ meets the demand of heat-supply load and the high heating temperature at the same time. The backwater temperature can take the optimal value according to the curve. Namely the supply water temperature and the return water temperature are $102^{\circ} \mathrm{C}$ and $45^{\circ} \mathrm{C}$. Heat pump COP is 1.81.This method can achieve high temperature hot water need for the traditional heating. To achieve better thermal efficiency, the reduction the return water temperature also need the improvement of heat transfer technology. But with the increase of heating temperature difference, the transmission capacity of heat-supply network is improved and the transmission distance is extended. So this scheme is suitable for heat user who has high heating temperature requirement, farther heating distance, and strong heating temperature control ability.

Scheme c meets the demand of heat-supply load and the temperature of supply and return water at the same time. Namely the supply and return water temperature is $102{ }^{\circ} \mathrm{C}$ and $65{ }^{\circ} \mathrm{C}$. The heat pump COP is 1.73 . This heating mode completely meets all parameters of the heat-supply network and is suitable for user with inherent parameters of heat supply network.

The thermal efficiency was calculated to compare three kinds of heating schemes, and the results were shown in Table 1:

Table 1 Contrast of three kinds of heating schemes in thermal economy

\begin{tabular}{llll}
\hline & Scheme a & Scheme b & Scheme c \\
\hline $\begin{array}{l}\text { Design power of heat } \\
\text { pump/MW }\end{array}$ & 195 & 119.8 & 78.8 \\
$\begin{array}{l}\text { Waste heat heating } \\
\text { amount/GJ } \mathrm{h}^{-1}\end{array}$ & 314.15 & 193.01 & 119.78 \\
$\begin{array}{l}\text { Energy production } \\
\text { increment } / \mathrm{kg} \cdot \mathrm{h}^{-1}\end{array}$ & 19679.7 & 14361.7 & 8546.7 \\
$\begin{array}{l}\text { Actual energy } \\
\text { production } / \mathrm{kg} \cdot \mathrm{h}^{-1}\end{array}$ & 292944 & 287626 & 281811 \\
$\begin{array}{l}\text { Actual cycle efficiency } \\
\text { Thermoficated generating rate } \\
/ \mathrm{kW} \cdot \mathrm{h} \cdot \mathrm{GJ}^{-1}\end{array}$ & 0.3957 & 0.3854 & 0.3767 \\
\hline
\end{tabular}

\section{Influence of absorption heat pump heating on thermal power plant economy}

From thermodynamic calculation results of the $330 \mathrm{MW}$ coal-fired when it is under rated conditions, the power plant thermal efficiency is 0.4112 . When the common heat exchange system is used to supply heat, heating thermoficated generating rate is $377.66 \mathrm{~kW} \cdot \mathrm{h} \cdot \mathrm{GJ}^{-1}$, generating capacity is $273264.3 \mathrm{~kW} \cdot \mathrm{h}$ and actual cycle efficiency is 0.3563 . When the lithium bromide absorption heat pump system is applied to recover low temperature waste heat of circulating cooling water, thermoficated generating rate, generating capacity and cycle efficiency are improved due to reduction of steam extraction amount ,no matter adopting scheme a, b or c. For example, when 
scheme a is adopted thermoficated generating rate, generating capacity and cycle efficiency are respectively improved to $397.22 \mathrm{~kW} \cdot \mathrm{h} \cdot \mathrm{GJ}^{-1}, 292944 \mathrm{~kW} \cdot \mathrm{h}$ and 0.3957 .Therefore, the application of heat pump technology to recycle power plant waste heat of circulating cooling water can improve waste heat utilization rate and thus improve thermal efficiency.

\section{Conclusion}

In this paper, the heating load of a northern city and the thermal system diagram of a $330 \mathrm{MW}$ unit under rated heating condition were adopted, and one day run log of the heat-supply network was referred to determine heating parameters. When absorption heat pump system is applied to recover waste heat of power plant exhaust steam, the influences of different supply and return water temperature of heat supply network on economy were analyzed. The best supply and return water temperature are $80^{\circ} \mathrm{C}$ and $45^{\circ} \mathrm{C}$ when economic benefit is considered. Besides, three kinds of heating schemes are supplied and thermal power plant can choose one suitable scheme according to the requirement of heat users. The results show that the application of heat pump to recover power plant waste heat can improve thermal efficiency of power plant.

\section{Acknowledgement}

This project is supported by Xi'an Science and Technology Program CXY1433(5) and China Scholarship Council Program.

\section{References}

[1]Liu Zhongbing, Zhang Ling, Yang Zhang, et al. Experimental Study of Thermoelectric Heat Pump Water Heater with Exhaust Heat Recovery from Kitchens[J]. Journal of Hunan University(Natural Sciences),2009 (5) 131-135.

[2]CHEN Zeshao, TAO Wenquan, et al. Performance analysis of air-water dual source heat pump water heater with heat recovery[J]. Science China, 2012 (8) 2148-2156.

[3]Mi Jianhua. Issues Influencing Power Energy Efficiency in the 11th Five-Year Plan Period[J]. Electricity, 2006 (3) 36-39.

[4]Zheng Dingyong. On the Development of China's Thermal Power in the 21st Century while Saving the Energy and Protecting the Environment[J]. Electricity, 1996 (9) 16-18.

[5]MA Qiang, WANG Ruzhu, LUO Lingai, et al. Transportation of low-grade thermal energy over long distance by ammonia-water absorption[J].Chinese Science Bulletin, 2009 (5) 948-957.

[6]Shu Haiwen, Lin Duanmu, et al. The Proper Scale and Energy Efficiency Requirement of Seawater Source Heat Pump District Heating System[C].The First International Conference on Building Energy and Environment Proceeding, 2008.7. 